\title{
Oxidation and oxide spallation of heat resistant cast steels for superplastic forming dies
}

\author{
S. Baleix, G. Bernhart, P. Lours * \\ CROMeP-Research Centre on Tools, Materials and Processes, Ecole des Mines d'Albi-Carmaux, Campus Jarlard, 81013 Albi cedex 09, France
}

\begin{abstract}
The oxidation and oxide spallation behaviour of austenitic and ferritic heat resistant cast steels used for manufacturing superplastic forming dies is investigated in isothermal and cyclic conditions. Gravimetric, microstructural and mechanical approaches are utilised to address the oxidation and spallation kinetics, to determine the nature of oxides grown at the surface of the materials and to discriminate the different routes to spallation depending on the substrate metallurgical structure and the oxidation conditions. It is shown that both types of material develop similar oxide scales with similar kinetics. The ferritic alloys appear to be more resistant to oxide spallation than the austenic alloys. The decrease of the fracture energy at the interface substrate/oxide during oxidation resulting from an aggregation of interfacial defects, causes spallation by wedging and buckling for thin and thick oxide layers, respectively.
\end{abstract}

Keywords: Superplastic forming tools; Heat resistant cast steel; Oxidation; Spallation; Thermal stresses; Strain energy models

\section{Introduction}

Superplastic forming (SPF) consists in blowing sheets, located within a mould, into shape using argon pressure [1]. Various materials can be formed superplastically provided the microstructure of the material, the temperature and the strain rate utilised are appropriate. In the case of titanium alloys, SPF process is carried out at temperature ranging from 850 to $950{ }^{\circ} \mathrm{C}$ and requires the use of heat resistant cast steels as tooling materials. These materials are commonly used for applications where service temperatures exceed $700{ }^{\circ} \mathrm{C}$, e.g. in petrochemical furnaces, cement mill and steel mill equipment and oil refinery furnaces. Selection of tool materials for the application includes consideration of the hot corrosion resistance, for which a high amount of chromium is recommended, and the mechanical strength provided by the addition of nickel and carbide forming elements [2]. Depending mainly on the nickel content, these materials are either austenitic or ferritic.

\footnotetext{
* Corresponding author. Tel.: + 33-563-493-078; fax: +33-563493-242.

E-mail address: lours@enstimac.fr (P. Lours).
}

Dies are cyclically withdrawn from the heating press in order to extract the shaped parts and load new sheets. Thermal stresses generated by the successive heating and cooling of the tool, in addition to the press clamping load and the forming pressure may cause permanent distortion of the die. In addition, oxidation and oxide spallation may alter the surface of the mould, thereby affecting the surface quality of the shaped SPF parts.

The present investigation focuses mainly on this type of tool damage. The oxidation and spallation behaviour of austenitic and ferritic heat resistant cast steels is investigated in isothermal and near service thermal cycling conditions. Focus is placed on the spallation behaviour of the oxide grown at the surface of the materials when exposed to high temperature cycles using thermogravimetric and mechanical approaches.

\section{Experimental}

Thermal cycles typical of the SPF process have been measured on industrial tools. In situ monitoring of the temperature at the surface of the tool was performed 
using both infra-red thermography and thermocouples [3]. For the industrial case investigated, data show that the forming temperature is close to $900{ }^{\circ} \mathrm{C}$ and that withdrawing of the tool from the press-furnace results in a cooling that, depending on the location at the surface of the die, does not exceed $200{ }^{\circ} \mathrm{C}$. Due to geometrical effects, high thermal gradients occur at the surface of the tool: salient edges of the die exhibit the most pronounced cooling while confined areas subject to radiation of opposing parts remains almost at constant temperature during the process. In any case, tools are subject to a final return to room temperature following the manufacturing of a whole bench of SPF parts.

Tool materials were oxidised isothermally at temperature ranging from 750 to $1050{ }^{\circ} \mathrm{C}$ and cyclically for exposure time up to around $700 \mathrm{~h}$. The characteristics of the oxidation cycles are given in Table 1 .

Special ingots were cast to obtain the required structure typical of SPF dies. Those ingots show a coarse macrostructure composed of columnar and equiaxed zones. The microstructure is characterised by the precipitation of primary interdendritic carbides issued from minor segregation as the alloy solidifies and fine secondary intradendritic carbides promoted by thermal ageing treatment.

Table 2 gives the ranges of weight percent compositions for the investigated tool materials along with pertinent thermal and mechanical properties. $\alpha_{s}-\alpha_{o}$ refers to the difference in thermal expansion coefficient between the substrate, either austenitic or ferritic, and chromia which is the main oxide that grows at the surface of both materials.

Oxidation coupons are extracted from the columnar zone of the ingot in the shape of chamfered discs (diameter $29 \mathrm{~mm}$, thickness $4 \mathrm{~mm}$ ). For each test temperature and thermal cycle, specimens, contained in crucibles, are cooled to room temperature after different exposure periods for gravimetric measurement of the extent of attack and microstructural investigation. Three different measurements are performed: (i) the mass of specimens within their crucibles which includes the amount of spalled oxide, i.e. the so-called gross weight change $(\Delta m / S)_{\text {gross }}$, (ii) the mass of the specimens alone excluding the mass of spalled oxide, i.e. the net weight change $(\Delta m / S)_{\text {net }}$ (the difference between those mass changes is the total mass of spalls $(\Delta m /$ $S)_{\text {spalled}}$, and in the case of cyclic oxidation, (iii) the mass of the oxide that spalled during cycling prior to the final return to room temperature $(\Delta m / S)_{\text {spalled. }}^{\text {cycling }}$. These three measurements allow to derive both the oxidation and the spallation kinetics and to monitor the amount of oxide that spalls when materials are subjected to thermal cycling.

Additional thermo-gravimetric analysis (TGA) is performed also in order to validate the data obtained from furnace oxidation and to monitor the continuous weight change versus exposure time that can reveal details not shown in the 'one specimen per exposure time' plot. The microstructural investigation of oxidised specimens are carried out using scanning electron microscope (SEM), electron probe micro-analysis (EPMA) and X-ray diffraction (XRD) and additional parameters required to address the spallation mechanisms are determined using image analysis of SEM micrographs and acoustic emission (AE) of oxidised specimens upon cooling (specimens for AE investigation are $50 \mathrm{~mm}$ long cylinders with 3 and $6 \mathrm{~mm}$ in diameter).

Table 1

Characteristic of the oxidation cycles

\begin{tabular}{lllllr}
\hline & Exposure at $T_{\max }$ & Exposure at $T_{\min }$ & Heating rate $\left(\mathrm{K} \mathrm{min}^{-1}\right)$ & Total exposure (h) & Total cycles \\
\hline Cycle 1 & $5 \mathrm{~h}$ at $950{ }^{\circ} \mathrm{C}$ & $0.2 \mathrm{~h}$ at $750{ }^{\circ} \mathrm{C}$ & 8 & 720 & 120 \\
Cycle 2 & $5 \mathrm{~h}$ at $950^{\circ} \mathrm{C}$ & $2 \mathrm{~h}$ at $350^{\circ} \mathrm{C}$ & 4 & 672 & 56 \\
Cycle 3 & $5 \mathrm{~h}$ at $950^{\circ} \mathrm{C}$ & $1 \mathrm{~h}$ at $25^{\circ} \mathrm{C}$ & 62 & 663 & 102 \\
\hline
\end{tabular}

Table 2

Properties of the investigated alloys (subscripts $o$ and $s$ refer to oxide and substrate)

\begin{tabular}{|c|c|c|c|c|c|c|c|c|c|}
\hline & \multicolumn{6}{|c|}{ Nominal composition (wt.\%) } & \multirow{2}{*}{$\frac{\alpha_{s}}{10^{-6}{ }^{\circ} \mathrm{C}^{-1}}$} & \multirow{2}{*}{$\frac{E_{s}}{\mathrm{GPa}}$} & \multirow{2}{*}{$\frac{\alpha_{s}-\alpha_{o}}{10^{-6}{ }^{\circ} \mathrm{C}^{-1}}$} \\
\hline & $\mathrm{C}$ & $\mathrm{Cr}$ & $\mathrm{Ni}$ & $\mathrm{Si}$ & $\mathrm{Mn}$ & $\mathrm{Fe}$ & & & \\
\hline Austenitic & $0.05-0.6$ & $24-29$ & $33-52$ & $<2$ & $<2$ & balance & 18 & 120 & 9.5 \\
\hline Ferritic & $0.5-0.9$ & $24-28$ & $<1$ & $<2$ & $<2$ & balance & 12 & 110 & 3.5 \\
\hline
\end{tabular}




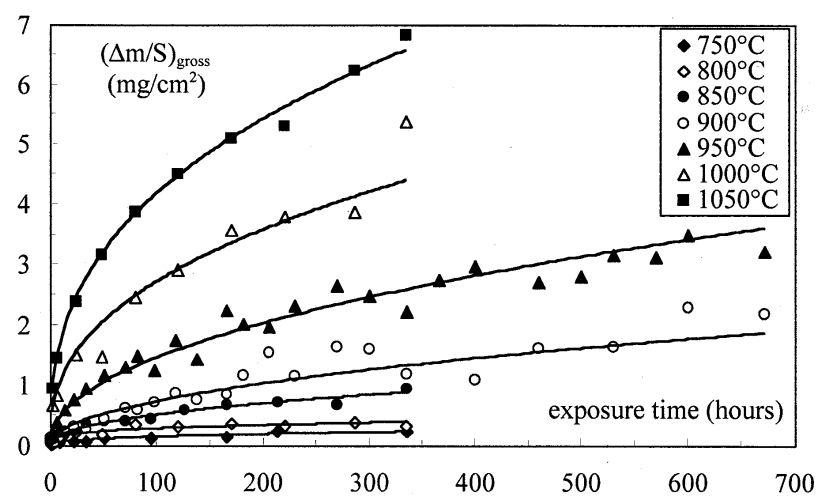

(a)

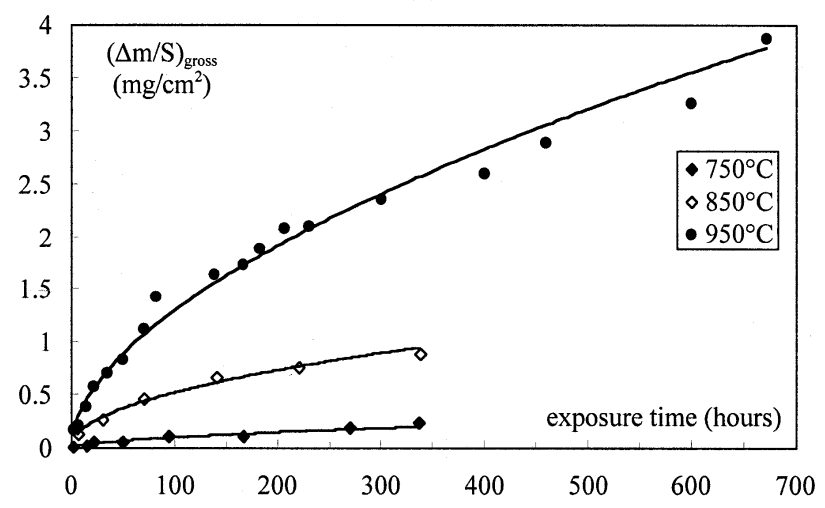

(b)

Fig. 1. Isothermal furnace oxidation kinetics at different temperatures of the austenitic alloy (a) and the ferritic alloy (b).

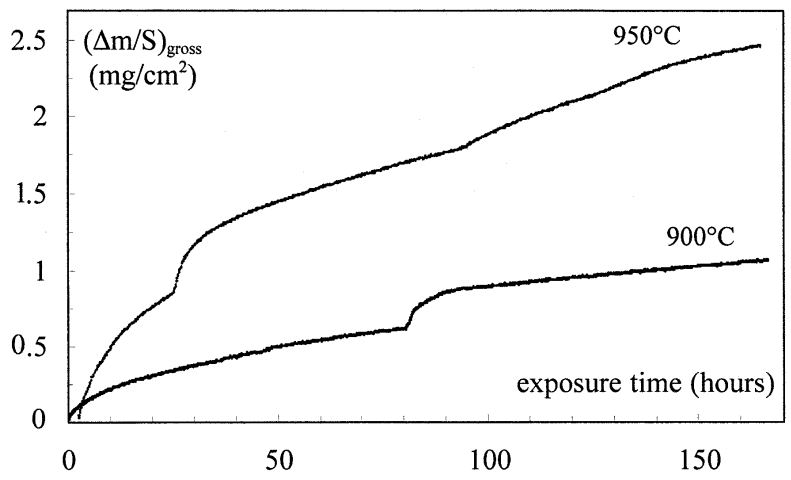

Fig. 2. Isothermal TGA oxidation kinetics of the austenitic alloy.

\section{Gravimetric results}

\subsection{Gross mass gain measurements}

The isothermal oxidation kinetics of both the austenitic and the ferritic alloys are given in Fig. 1(a) and (b). Gravimetric measurements show that the kinetics of oxidation exhibits a parabolic behaviour where the gross weight change is proportional to the square root of the exposure time in the range 850-1050 ${ }^{\circ} \mathrm{C}$ for the austenitic alloy and $750-950{ }^{\circ} \mathrm{C}$ for the ferritic alloy. Below $850{ }^{\circ} \mathrm{C}$ (i.e at 750 and $800^{\circ} \mathrm{C}$ ) the oxidation kinetics of the austenitic alloy is essentially sub-parabolic as plots can be fitted satisfactorily using a power law with a power exponent around 0.3. Change from the sub-parabolic to parabolic regime of oxidation can result from the occurrence of growth stress [4] within the oxide scale large enough to provoke the formation of cracks offering an easy path to oxygen that results in an enhancement of the oxidation process at the interface substrate/oxide. The related increase of the weight gain is the signature of such a mechanism. Though quite tricky to identify because of the limited number of specimens available for weighting, the associated discontinuity of the kinetics plots can be observed for temperatures above or equal to $850{ }^{\circ} \mathrm{C}$ (Fig. 1(a)). However, this discontinuity is unambiguously shown in Fig. 2, where the oxidation kinetics of the austenitic alloy, monitored with a thermogravimetric analyser, is plotted for exposure at 900 and $950{ }^{\circ} \mathrm{C}$.

Fig. 3 is an Arrhenius plot of the variation of the parabolic rate constant with the reciprocal temperature. Calculated data fit a single regression line in the respective temperature range discussed above, showing that the oxide growth is thermally activated with an activation energy very close for both materials, around $2.5 \times$ $10^{5} \mathrm{~J} \mathrm{~mol}^{-1}$, typical of chromia forming alloys [5].

The cyclic oxidation kinetics measured as function of the number of cycles is given in Fig. 4(a) and (b). A thorough examination of this kinetics, plotted versus the exposure time, shows that it is close to being parabolic. The oxidation rate of cycle 1 and isothermal exposure at $950{ }^{\circ} \mathrm{C}$ are very close, resulting in similar parabolic rate constants. The slightly lower mass gain of specimens in the case of cycle 1, compared to isothermal oxidation, results from an overall shorter exposure at $950{ }^{\circ} \mathrm{C}$. Indeed, for cycle 1 , cooling to, heating from and dwell at $750{ }^{\circ} \mathrm{C}$ represents only $14 \%$ of the total exposure. Similarity of both kinetics also suggests that the repeated cooling of specimens to 750 ${ }^{\circ} \mathrm{C}$ does not provoke oxide scale spallation which might initiate a change in the oxidation kinetics.

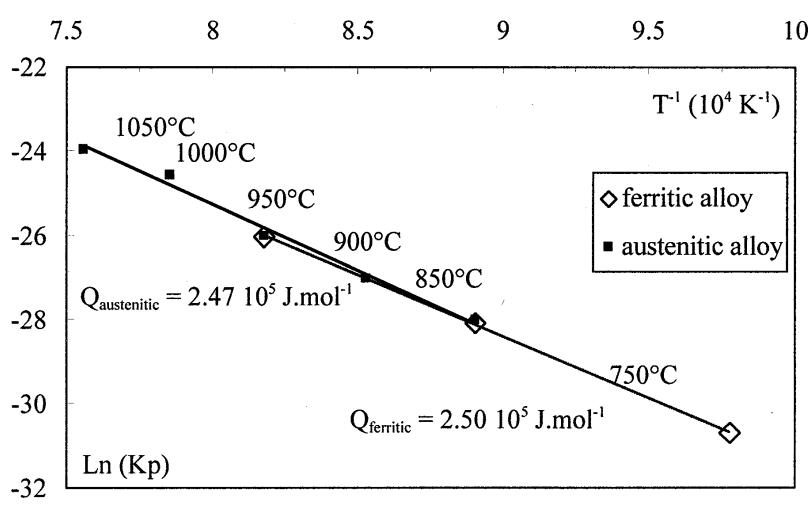

Fig. 3. Arrhenius plot of oxidation rate constant $K_{p}$ versus reciprocal temperature. 


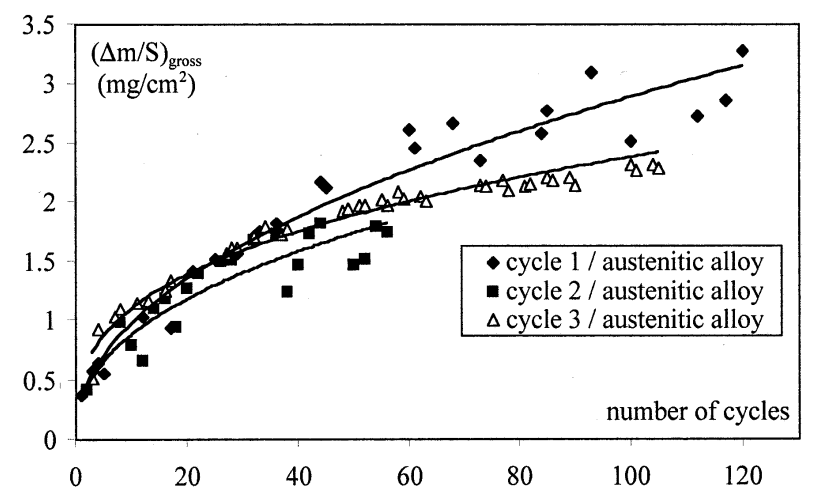

(a)

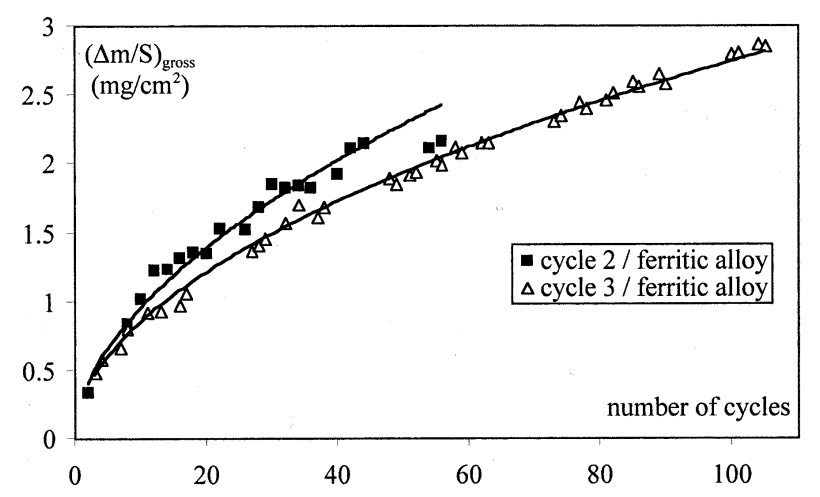

(b)

Fig. 4. Cyclic furnace oxidation kinetics of the austenitic alloy (a) and the ferritic alloy (b).

In the case of cycles 2 and 3, for which the lowest temperatures are $350{ }^{\circ} \mathrm{C}$ and room temperature, respectively, the oxidation rates are much lower. Under these oxidation conditions the oxide scales grow significantly only when specimens are exposed to temperatures above $750{ }^{\circ} \mathrm{C}$, the lowest isothermal temperature tested for which oxide growth is very slow (Fig. 1). For cycles 2 and 3 , these efficient oxidation periods are respectively 275 and $515 \mathrm{~h}$ while the total exposure times are circa $670 \mathrm{~h}$ in both cases.

\subsection{Effect of cooling on the mechanical failure of the scales}

Two types of cooling are imposed to the oxidation specimens. Isothermally oxidised specimens are cooled individually to room temperature after different exposure times. Cyclically oxidised specimens are first cooled from the high to the low temperature typical of the cycle and then finally returned to room temperature after various exposure times. This allows to discriminate the influence of the amplitude of the temperature drop on the amount of oxide that spalls under the effect of the thermal compressive stress occurring in the oxide scale.

For isothermal exposure at $750{ }^{\circ} \mathrm{C}$, cooling of specimens to room temperature does not provoke any spal- lation. The weight change including and excluding the mass of spalled oxide, $(\Delta m / S)_{\text {gross }}$, and $(\Delta m / S)_{\text {net }}$, are similar in the whole range of exposure. At temperatures above $800{ }^{\circ} \mathrm{C}$ for the austenitic alloy and $900{ }^{\circ} \mathrm{C}$ for the ferritic alloy, the two curves diverge indicating that some oxide spalls upon cooling to room temperature.

Fig. 5(a) is a plot of the gross $(\Delta m / S)_{\text {gross }}$ and the net $(\Delta m / S)_{\text {net }}$ weight change versus exposure time for the austenitic specimen oxidised in cycle 1 . The difference between the two curves, $(\Delta m / S)_{\text {spalled }}$, corresponds to the amount of oxide that spalls upon cooling to room temperature. Up to a threshold exposure time circa 54 $\mathrm{h}$ corresponding to nine cumulative cycles, both plots are similar indicating that no significant spallation occurred. Below this critical exposure, the attack of the alloy is essentially protective and the two curves are close to parabolic. Above this exposure corresponding to the onset of spallation, the two plots diverge as the amount of spalled oxide gradually increases. Image analysis of SEM micrographs revealed that as much as $70 \%$ of the oxide scale has spalled from the surface of the coupons after $662 \mathrm{~h}$ of exposure [6]. The amount of oxide that spalls depends on the temperature and the exposure time, i.e. on the oxide thickness. Accordingly, these threshold exposure times decrease as the exposure temperature increases.

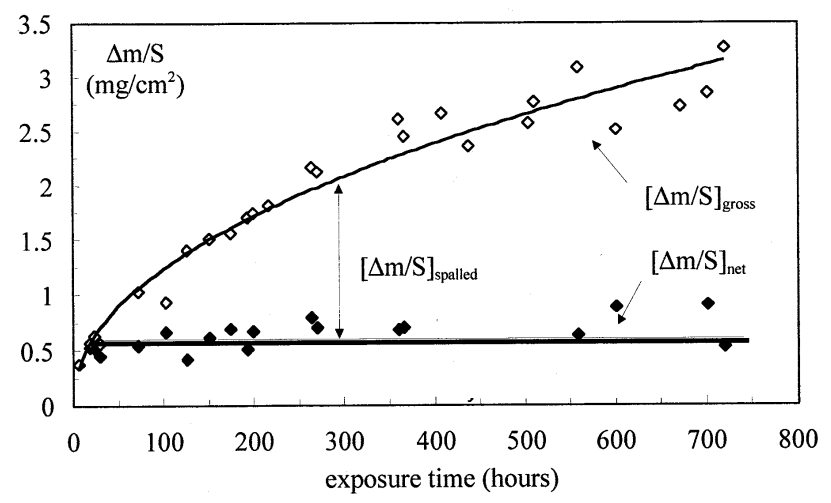

(a)

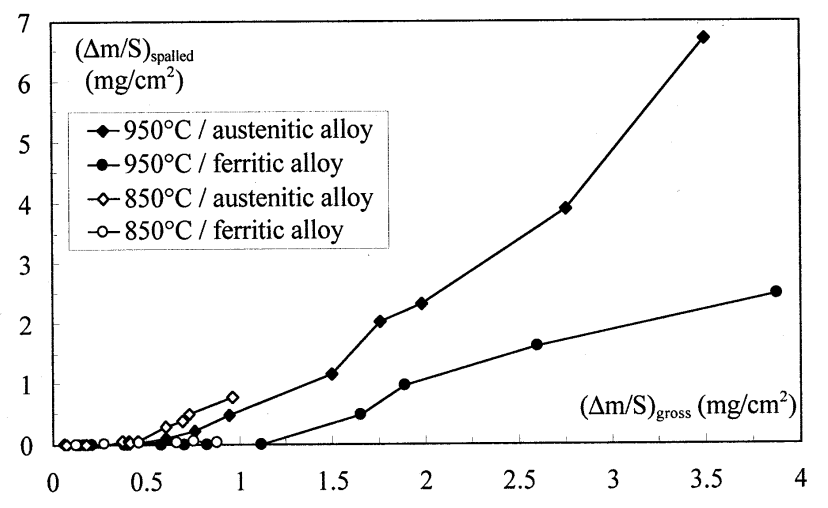

(b)

Fig. 5. Oxidation and spallation kinetics of the austenitic alloy exposed to cycle 1 (a) and mass of spalled oxide due to room temperature cooling versus gross weight gain (b). 


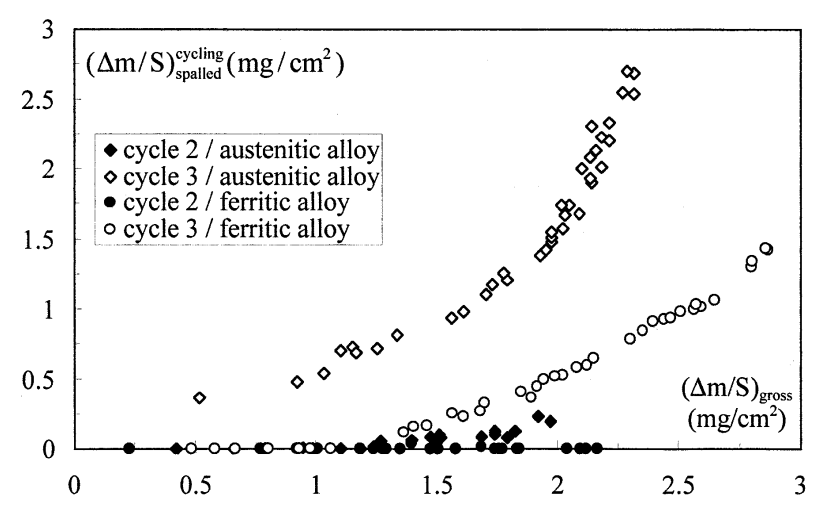

Fig. 6. Mass of spalled oxide due to cycling versus gross weight gain.

Fig. 5(b) compares $(\Delta m / S)_{\text {spalled }}$ and $(\Delta m / S)_{\text {gross }}$ for the austenitic and the ferritic material isothermally oxidised at 850 and $950^{\circ} \mathrm{C}$ and subsequently cooled to room temperature. The figure shows that the ferritic material does not spall after exposure at $850{ }^{\circ} \mathrm{C}$ while the austenitic material is subject to spallation as the gross weight change reaches $0.5 \mathrm{mg} \mathrm{cm}^{-2}$. Following exposure at $950{ }^{\circ} \mathrm{C}$, both oxidised alloys tends to spall. The onset of spallation for the austenitic and the ferritic alloys corresponds, respectively to a gross weight change circa $0.5 \mathrm{mg} \mathrm{cm}^{-2}$, consistently with the data in Fig. 5(a), and $1 \mathrm{mg} \mathrm{cm}^{-2}$. In the case of the ferritic alloy exposed at $850{ }^{\circ} \mathrm{C}$ up to $336 \mathrm{~h}$, the thermal activation is too low to grow an oxide scale thick enough to reach the critical mass gain that initiates spallation. Once the onset of spallation is reached, the cumulative mass of spalled debris increases quasi-linearly with further mass gain. The rate, with respect to gross mass gain, at which the extent of spallation increases is alloy specific, i.e. is greater for the austenitic than for the ferritic alloy.

The differences in behaviour between the austenitic and the ferritic alloy is due both to the difference in the stress generated within the oxide scale upon cooling and the difference in the extent of stress relief afforded by the plastic deformation of the alloy substrate $[7,8]$. It is assumed generally that the compressive stress within the oxide upon cooling is proportional to $\Delta \alpha=\left(\alpha_{s}-\alpha_{o}\right)$, the difference in thermal expansion coefficient between the oxide and the substrate. In such condition, taking into account the value of $\Delta \alpha$ given in Table 2, this stress will be greater in the case of the austenitic alloy. In addition, the austenitic alloy is more creep resistant than the ferritic alloy, resulting in lower stress relief during cooling and earlier spallation.

In order to approach the critical temperature drop to initiate spallation, the amount of oxide that spalls during thermal cycling are measured. It is shown that, for both types of alloy, no significant spallation occurs in the case of cycle 1 for which $\Delta T=950-750=200{ }^{\circ} \mathrm{C}$ [9]. In the case of cycle $2\left(\Delta T=950-350=600{ }^{\circ} \mathrm{C}\right)$, some spallation is detected for the austenitic alloy while the oxide grown on the ferritic alloy remains adherent up to the maximum exposure time (Fig. 6). Note that in this case the critical mass gain $\left(1.2 \mathrm{mg} \mathrm{cm}^{-2}\right)$ exceeds the value determined for the return to room temperature (Fig. 5). The discrepancy may be accounted for, considering the creep relaxation of stress in the oxide during cooling. In the case of cycle 2 , the cooling rate is low, i.e. $4 \mathrm{~K} \mathrm{~min}^{-1}$ (Table 1), which gives more time for the substrate to relieve the stress generated in the scale by thermal transients. In other word, the cooling rate dictates the time-scale during which the substrate can deform plastically and, as a consequence, the extent of stress relief. In cycle 3, which includes the return to room temperature after every cycle, the cooling rate is high, i.e. $62 \mathrm{~K} \mathrm{~min}^{-1}$ (Table 1) and the onset of spallation is close to that measured after cooling to room temperature following isothermal and cyclic exposure: 0.5 and $1 \mathrm{mg} \mathrm{cm}^{-2}$, respectively, for the austenitic and the ferritic alloy (Fig. 6).

\section{Morphology and nature of the oxides}

Fig. 7 shows the surface of the austenitic and the ferritic material after various oxidising conditions. The figure shows that the morphology of the oxide is similar for both materials. For low oxidation temperature and/ or short exposure time (Fig. 7(a) and (b)), the thin oxide grown at the surface of the coupons lies along the machining grooves of the substrate. The top surface is a flat scale of pure chromia $\mathrm{Cr}_{2} \mathrm{O}_{3}$ on which, if the temperature and/or the exposure time are sufficiently high, nodules of spinel $\mathrm{MnCr}_{2} \mathrm{O}_{4}$ are located (Fig. 7(b)). The formation of the spinel results from the concurrent fast diffusion of $\mathrm{Mn}$ through the chromia scale as the chromium reservoir in the near surface region gradually depletes. When the exposure time and/or the thermal activation are sufficient, the spinel layer grows laterally and forms, in the shape of highly faceted crystallites, on the whole surface of the specimen (Fig. 7(c) and (d)).

Cross-sectional investigation confirms the multi-layer structure of the scale (Fig. 8). In addition to the chromia and the spinel, the SEM and EPMA analyses reveal the presence of a thin irregular scale of silicon rich oxide lying at the interface between the substrate and the oxide. XRD analysis of the austenitic specimen oxidised at 750,850 and $950{ }^{\circ} \mathrm{C}$ during $336 \mathrm{~h}$ being detailed in [9] shows, that the nature of the oxides that grow at the surface of the specimen remains the same whatever the exposure temperature is. The silicon rich oxide does not show on the XRD spectrum and is assumed to be amorphous silica [10].

The spalls are generally elongated along the machining grooves of the substrate. This is particularly true for short time exposure and/or low oxidation temperature where the thin oxide grown at the surface of the 
coupons delineates accurately the profile of the substrate surface. Following exposure at $750{ }^{\circ} \mathrm{C}$, a temperature where no spallation could be detected gravimetrically, microstructural investigation shows that some spalling occurred (Fig. 9(a)). Backscattered electron SEM images coupled with energy dispersive spectroscopy (EDS) of the surface of specimens allows

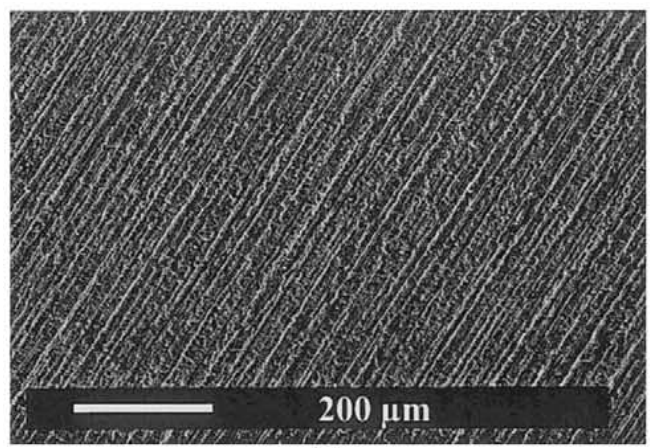

(a)

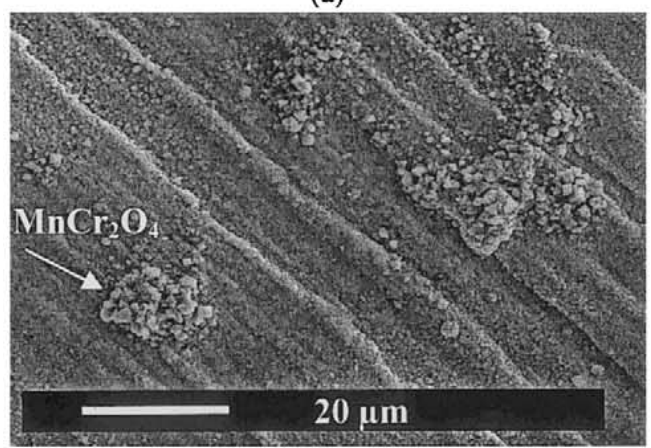

(b)

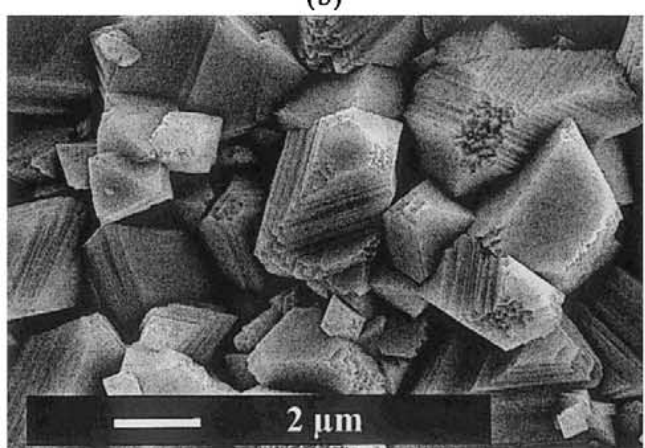

(c)

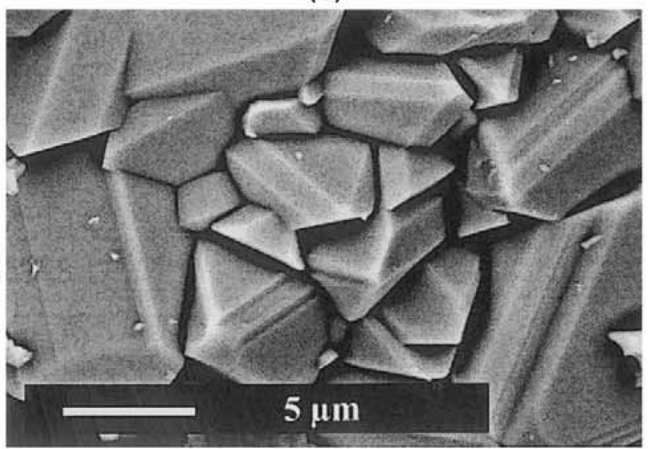

(d)

Fig. 7. Morphology of the oxide scale for the ferritic material exposed at $950{ }^{\circ} \mathrm{C}$ for $6 \mathrm{~h} \mathrm{(a)}$, the austenitic material exposed at $750{ }^{\circ} \mathrm{C}$ for 50 $\mathrm{h}$ (b), the ferritic material exposed in cycle 2 for $663 \mathrm{~h}$ (c) and the austenitic material exposed at $1000{ }^{\circ} \mathrm{C}$ for $336 \mathrm{~h}$ (d).

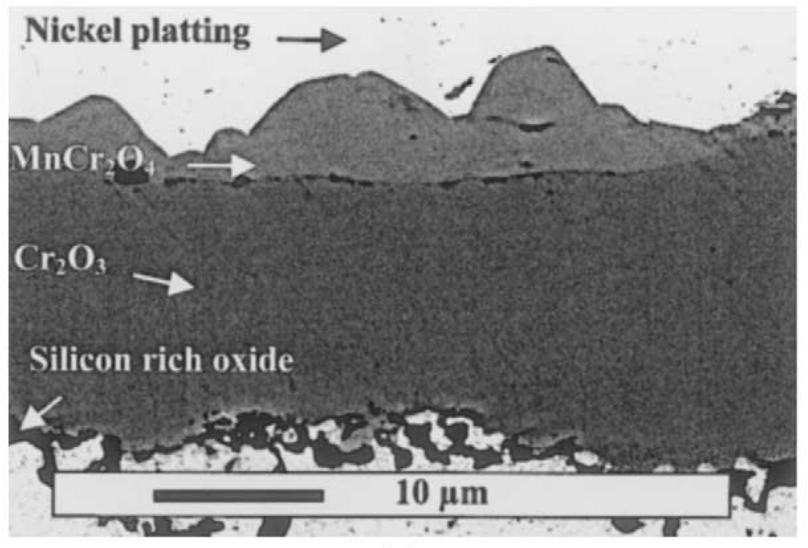

(a)

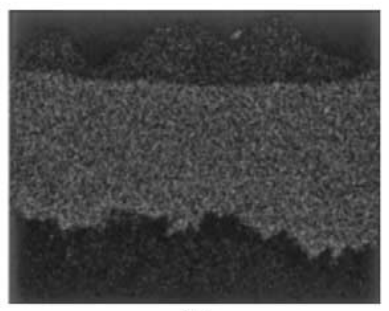

(b)

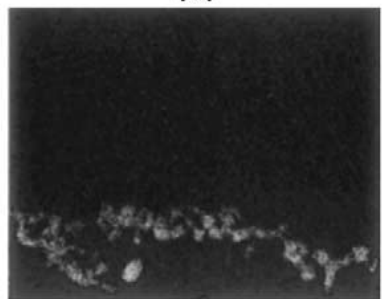

(d)

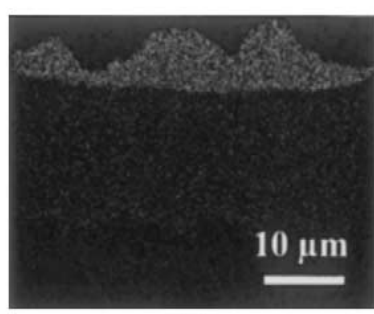

(c)

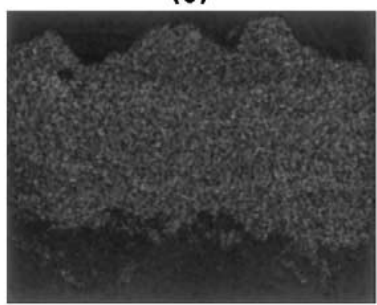

(e)
Fig. 8. Cross-sectional SEM micrograph of the austenitic alloy exposed at $950{ }^{\circ} \mathrm{C}$ for $600 \mathrm{~h}$ (a) and corresponding chromium (b), manganese (c), silicon (d) and oxygen (e) X-ray images.

the determination of the various phases involved in the oxidation and spallation process. Fig. 9(a) is a detail of a zone that suffered spallation. The oxide has partially fractured and detached, revealing the underlying substrate (centre and upper right of the image). The zones, where the oxide detached adhesively from the substrate are bordered by a fine strip of pure chromium oxide indicating concurrent spallation within $\mathrm{Cr}_{2} \mathrm{O}_{3}$ or at the interface $\mathrm{Cr}_{2} \mathrm{O}_{3} / \mathrm{MnCr}_{2} \mathrm{O}_{4}$. In order to investigate spallation quantitatively in areas large enough to be representative with a good resolution, acquisition of 3 by 2.8 $\mathrm{mm}$ images, corresponding to 30 joined fields subsequently assembled, is performed. The grey level images are segmented using two thresholds that discriminate the three phases showing at the surface of the oxidised and spalled specimens [6]. An example of such a processed image is given in Fig. 9(b) where the austenite substrate, $\mathrm{Cr}_{2} \mathrm{O}_{3}$ and $\mathrm{MnCr}_{2} \mathrm{O}_{4}$ are, respectively represented by the black, grey and white zones. The textured morphology of the spalls is observed clearly in the figure. The surface fraction of spalls including both 
those resulting from fracture along the substrate interface and within the chromia scale, circa $25 \%$ in the case shown in Fig. 9(b), tends to increase with the exposure time, i.e. the thickness of the oxide. The surface fraction of spall reaches 35 and $70 \%$, respectively in the case of cycle 2 and cycle 1 for the maximum exposure time indicated in Table 1.

The detailed morphology of a spalled area of a specimen exposed at $950{ }^{\circ} \mathrm{C}$ during $570 \mathrm{~h}$ is shown in Fig. 9(c). In this case, due to the long term exposure and the high oxidation temperature, the specimen de-

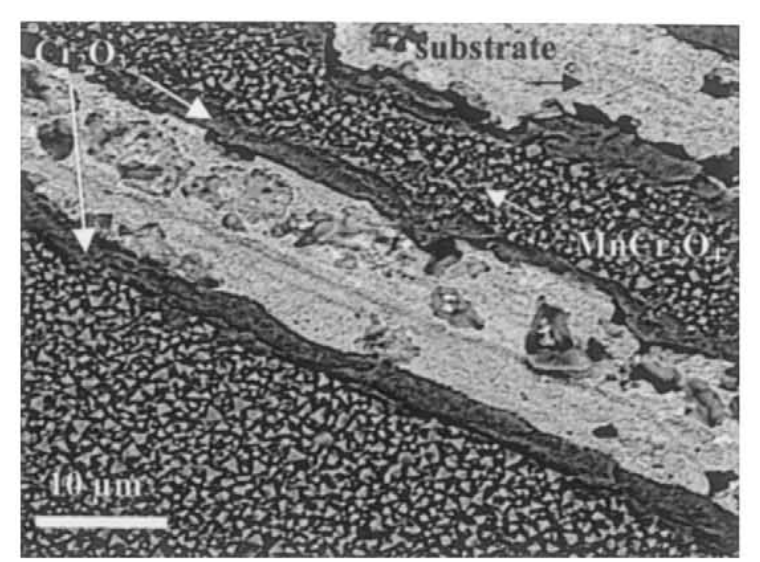

(a)

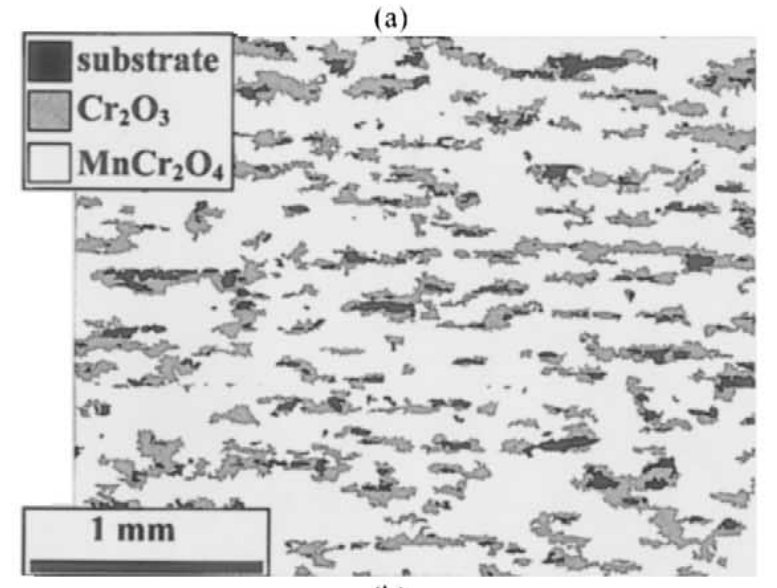

(b)

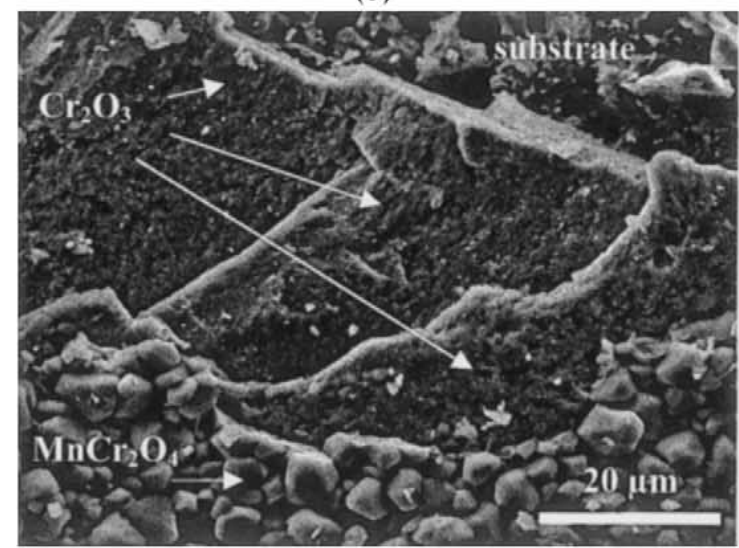

(c)

Fig. 9. Morphology of spalled zones for the autenitic material oxi-

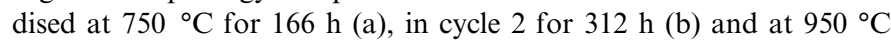
for $570 \mathrm{~h} \mathrm{(c)}$. veloped a quite thick oxide scale of circa $20 \mu \mathrm{m}$. The substrate where complete spallation occurred and the spinel where no spallation occurred can be, observed respectively at the top and the bottom of the image. The remaining part of the image consists of a step shaped chromia scale. Each single step corresponds to the location of a rupture within the scale resulting in the detachment of the oxide. The perfectly flat morphology of those steps suggests that fracture occurred along paths offering weak resistance to thermal stress generated during cooling of the specimen. The paths might correspond to interfaces between successively grown chromia scales. The scales may have grown following cracking of the external scale due to oxide growth stress and related oxygen uptake in the scale. This mechanism can be associated to the discontinuities in the oxidation kinetics discussed in Section 3.1, Fig. 2 corresponding to an increase in the rate of oxidation.

\section{Thermal stress in the oxide scales}

Gravimetric data show that the amount of spalled oxide as specimens are cooled is a function of the metallurgical structure of the substrate, i.e. the thermal and the mechanical properties of the alloy that suffers oxidation, the amplitude of the temperature drop imposed on the specimen and the gross weight gain of the specimen due to oxidation, i.e. the thickness of the oxide that grows on the surface of the specimen.

Assuming continuity of the strain at the interface substrate/oxide, negligible growth stress produced at the oxidation temperature and a creep rigid substrate; the stress generated in a single layer of oxide upon cooling is proportional to both the difference in thermal expansion coefficient between the oxide and the substrate and the temperature drop [11]. This simple thermoelastic approach accounts satisfactorily for the enhancement of spallation as the temperature drop increases as well as the differences in behaviour between the austenite and the ferrite [9]. Indeed, the higher the difference in thermal expansion coefficient between the substrate and the oxide, the higher is the compressive stress in the oxide scale.

However, the model fails to explain the higher propensity of the oxide to spall as the oxide thickens due to an increase in exposure time.

To take into account the stratified structure of the oxide scale, stress analysis of the multi-layer oxide scale configuration subject to surface cooling is addressed using the model proposed in [12] which was developed for coated continuous fibre composites. Assuming $n$ concentric scales and strain continuity at each interface, the expression of the thermoelastic radial $\sigma_{r r}$, tangential (hoop) $\sigma_{\theta \theta}$ and axial $\sigma_{z z}$ stresses may be written as: 


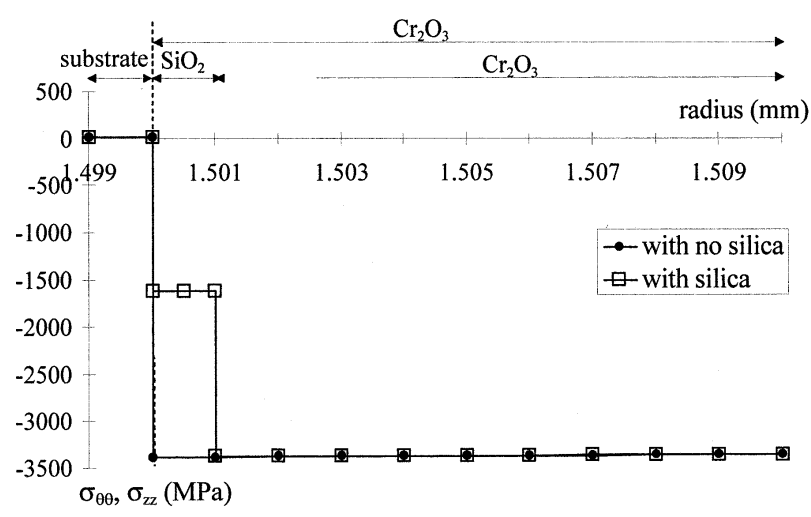

Fig. 10. Tangential and longitudinal (a) and radial (b) stresses in the thickness of a single and a twofold oxide scale.

$$
\begin{aligned}
\sigma_{r r}^{n}= & C_{r r}^{(n)}\left[A_{n}-\frac{B_{n}}{r^{2}}+C_{n}(r)-\frac{D_{n}(r)}{r^{2}}\right] \\
& +C_{r \theta}^{(n)}\left[A_{n}-\frac{B_{n}}{r^{2}}+C_{n}(r)-\frac{D_{n}(r)}{r^{2}}\right]+C_{r z}^{(n)} F \\
& -\beta_{1}^{(n)} T_{n}(r) \\
\sigma_{\theta \theta}^{n}= & C_{r \theta}^{(n)}\left[A_{n}-\frac{B_{n}}{r^{2}}+C_{n}(r)-\frac{D_{n}(r)}{r^{2}}\right] \\
& +C_{r r}^{(n)}\left[A_{n}-\frac{B_{n}}{r^{2}}+C_{n}(r)-\frac{D_{n}(r)}{r^{2}}\right]+C_{r z}^{(n)} F \\
& -\beta_{1}^{(n)} T_{n}(r) \\
\sigma_{z z}^{n}= & C_{r z}^{(n)}\left[A_{n}+C_{n}(r)\right]+C_{z z}^{(n)} E-\beta_{3}^{(n)} T_{n}(r) \\
\sigma_{r z}= & \sigma_{\theta z}=\sigma_{r \theta}=0
\end{aligned}
$$

where $r$ is the radial location, $A_{n}, B_{n}, C_{n}(r), D_{n}(r)$ and $F$ are constants or functions related to the geometry and the material stiffness coefficients $C_{i j}(j=r, \theta, z) . \beta_{1}^{(n)}$ and $\beta_{3}^{(n)}$ are functions depending on the stiffness and the thermal expansion coefficients and $T_{n}(r, t)$ is the temperature at location $r$ and time $t$ if transient simulation is performed. If uniform cooling is assumed, $T_{n}(r, t)=\Delta T$, the temperature drop. Taking into account the boundary conditions of the system, the resolution of the stress fields for $n$ layers is achieved by solving a linear system of $2 n$ equations for $2 n$ unknowns using the computer program MapleV ${ }^{\circledR}$ [9].

Theoretically, the sequence of oxides described in Section 4 and composed of $\mathrm{SiO}_{2}, \mathrm{Cr}_{2} \mathrm{O}_{3}$ and $\mathrm{MnCr}_{2} \mathrm{O} 4$ can be described analytically provided the thermomechanical properties of each oxide are known. Literature is quite poor in relating such properties, particularly for the spinel. As the consequence, the calculation was carried out in the case of a twofold oxide scale, being composed of $\mathrm{SiO}_{2}$ and $\mathrm{Cr}_{2} \mathrm{O}_{3}$. This choice, dictated by the constraints indicated above, is nevertheless adequate as the catastrophic spallation, leading to a loss of protectiveness of the material, mostly results from the failure and detachment of the oxide at the interface substrate/oxide.

Though unambiguously observed in cross-sectional
SEM investigation of oxidised coupons, the silicon rich oxide was not detected by X-ray diffraction analysis. It is concluded that this layer is amorphous $\mathrm{SiO}_{2}$, with low thermal expansion coefficient $\left(\alpha=0.510^{-6}{ }^{\circ} \mathrm{C}^{-1}\right)$ and Young's modulus $(E=70 \mathrm{GPa})$. Calculation is performed for a cylindrical specimen made of austenitic alloy with a radius of $1.5 \mathrm{~mm}$ overlaid by a thin $\mathrm{SiO}_{2}$ interlayer $(1 \mu \mathrm{m}$ thick $)$ and an outer thick $\mathrm{Cr}_{2} \mathrm{O}_{3}$ layer (10 $\mu \mathrm{m}$ thick).

Fig. 10 shows the results of the related calculation of the tangential and longitudinal stresses within the twofold oxide and, as a comparison, within a single $\mathrm{Cr}_{2} \mathrm{O}_{3}$. The stress is plotted versus the thickness in both the very near surface substrate $(1 \mu \mathrm{m})$ and across the oxide $(10$ $\mu \mathrm{m})$ for $\Delta T=930{ }^{\circ} \mathrm{C}$. Tangential and longitudinal stresses are equal in both sequences of oxides regardless of the thickness of the oxide. It is shown that the presence of the silicon rich oxide does not modify the stress in the chromia scale. The stress in the silicon rich oxide is about half of the stress in chromia.

\section{Spallation}

\subsection{Strain energy models}

The thermoelastic approach using different models either for flat or curved substrate and single or multilayer scale fails to explain the enhanced propensity of the oxide to spall on cooling when the oxide thickness, i.e. the exposure time, increases. To account for this discrepancy, it is necessary to introduce the so-called strain energy models in which the fracture energy at the interface metal/oxide is considered.

Depending on the oxide thickness and the strength of the metal oxide interface, two different routes for spallation are reported [13]. In the case of a strong interface, i.e. a high fracture energy, compressive shear cracking develops in the oxide. Decohesion and detachment of oxide particles upon further cooling is produced by wedge cracking at the interface metal/oxide in the region bounded by the shear cracks. The critical temperature drop $\Delta T_{c}^{w}$ to initiate spallation by wedging is given by:

$\Delta T_{c}^{w}=\left(\frac{\gamma_{F}}{\xi E_{o}(\Delta \alpha)^{2}\left(1-v_{o}\right)}\right)^{\frac{1}{2}}$

where $\gamma_{F}$ is the fracture energy of the metal/oxide interface.

In the case of a weak metal/oxide interface, i.e. for low fracture energy, the oxide may detach locally from the substrate resulting in the formation of buckles. Spallation occurs when through-thickness cracks develop in region of high tensile stress within the oxide. The critical temperature drop $\Delta T_{c}^{b}$ to initiate spallation by buckling is given by [14]: 
$\Delta T_{c}^{b}=\left(\frac{1.052 \xi^{4}}{R^{4}}+\frac{1.041 \gamma_{F}}{E_{o} \xi}\right)^{\frac{1}{2}} \frac{1}{\Delta \alpha}$

where $R$ is the radius of the area of decohesion.

Identification of the possible route to spallation requires the determination of the parameters $\gamma_{F}, R$ and $\Delta T_{c}$. The direct measurement of the fracture energy of the interface substrate/oxide is not easy to perform in the case of thin scales. The available experimental techniques including among others scratch test and interfacial indentation are reviewed in [15], but to date no universal and easy test providing reproducible and reliable results on interfacial adhesion exists. The fracture energy can be estimated indirectly by fitting the experimental data to the analytical plot of the critical temperature drop making assumptions, in the case of buckling, on the value of the spalled particle size. This method readily assumes both constant fracture energy and radius of spalled particles.

\subsection{Determination of the critical temperature drop for spallation}

The critical temperature drop to initiate spallation, $\Delta T_{c}$, can be measured by monitoring the AE of oxi-

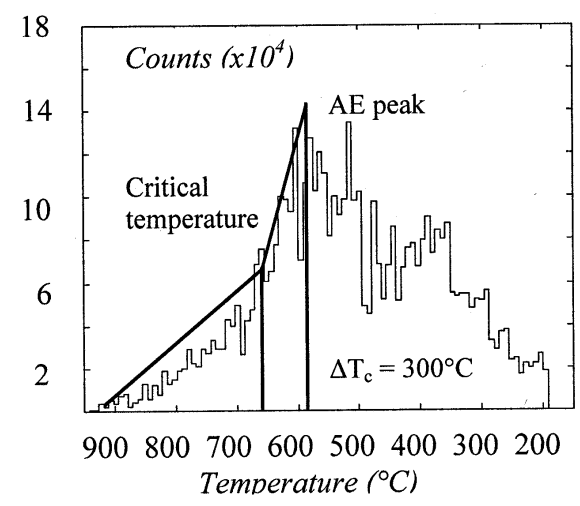

Fig. 11. Example of an acoustic emission spectra for the austenitic material oxidised during $168 \mathrm{~h}$ at $950{ }^{\circ} \mathrm{C}$ upon cooling to room temperature.

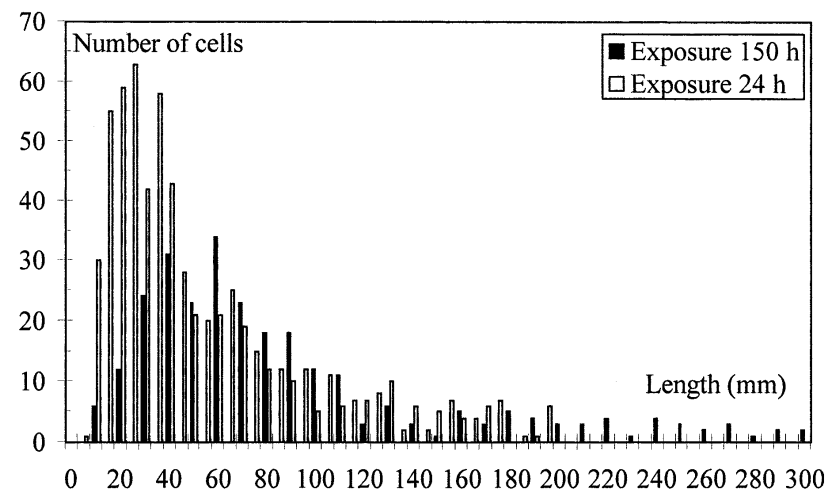

Fig. 12. Size distribution of spalling residues for the austenitic alloy oxidised for 24 and $150 \mathrm{~h}$ at $950{ }^{\circ} \mathrm{C}$. dised specimen upon cooling [16,17]. Fig. 11 presents an example of the AE spectra, where the number of counts is plotted versus the temperature, for a cylindrical austenitic specimen exposed at $950{ }^{\circ} \mathrm{C}$ during $168 \mathrm{~h}$, and cooled to room temperature.

A thorough examination of the quasi bell curve spectra shows that the rising part of the plots can be divided in two distinct zones which may correspond to the formation of cracks within the oxide and to the detachment of the oxide spall from the substrate. Oxide spallation is assumed to be completed as the peak of the curve is reached and the acoustic signal vanishes. The critical temperature that initiates spallation is taken as the temperature corresponding to the change in shape of the ascending part of the curve.

The critical temperature drop, measured for specimens exposed $24 \mathrm{~h}\left(\Delta T_{c}=475^{\circ} \mathrm{C}\right), 88 \mathrm{~h}\left(\Delta T_{c}=325^{\circ} \mathrm{C}\right)$ and $168 \mathrm{~h}\left(\Delta T_{c}=275^{\circ} \mathrm{C}\right)$ decreases as the exposure time, i.e. the thickness of the oxide increases. This shows that the energy required to provoke spallation decreases as the oxide thickens which may be accounted for either by a decrease of the mechanical strength of the oxide or a decrease of the adhesion at the interface substrate/oxide.

\subsection{Measurement of the spall size}

In the case of the buckling model, the critical temperature drop is expressed as a function of the radius of the area of decohesion $R$. An attempt is made to estimate this value by measuring the size of the spall area after oxidation and cooling of specimens by means of image analysis of SEM micrographs. The analysis is performed on 30 assembled joined fields representing areas of $3 \mathrm{~mm}$ by $2.8 \mathrm{~mm}$ as indicated in Section 4, Fig. 9(b) [6].

The size of the spalls may be approached using different parameters such as the length or the breadth of the rectangles that circumscribe the spalls, the area $S$ of the spalls, the equivalent diameter of the spalls defined as $2 \sqrt{S / \pi}$ or the perimeter length of the spalls. To account for the textured morphology of the spalls showing high aspect ratios, the length of the rectangles that circumscribe the spall is the preferred parameter to characterise the size of the spalls. The histogram in Fig. 12 gives the distribution of the number of spalls versus the spall length for two austenitic specimens exposed at $950{ }^{\circ} \mathrm{C}$, for 24 and 150 $\mathrm{h}$, then cooled to room temperature. The graph shows significant scattering of the data and a mean value of 70 and $150 \mu \mathrm{m}$ is calculated for 24 and $150 \mathrm{~h}$ exposure, respectively. This mean value increases as the exposure time, i.e. the oxide thickness, increases accordingly with the related enhancement of the spallation process. 


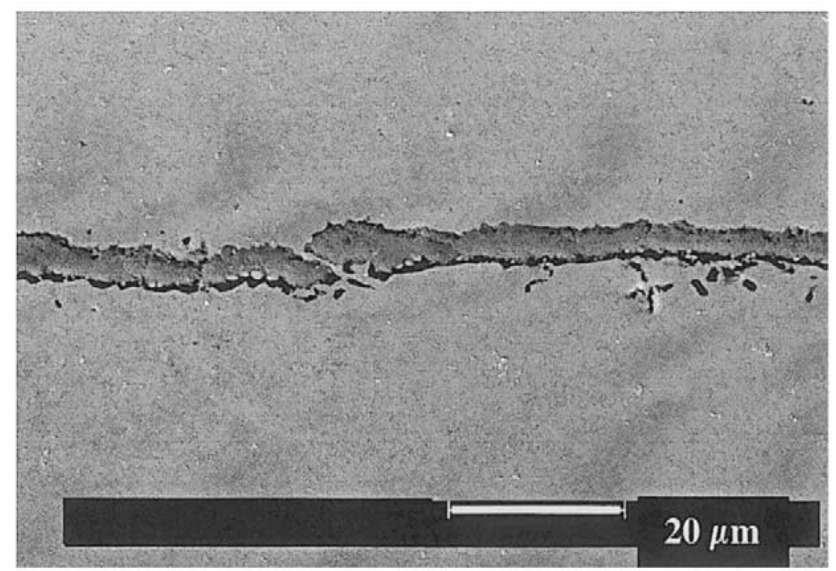

(a)

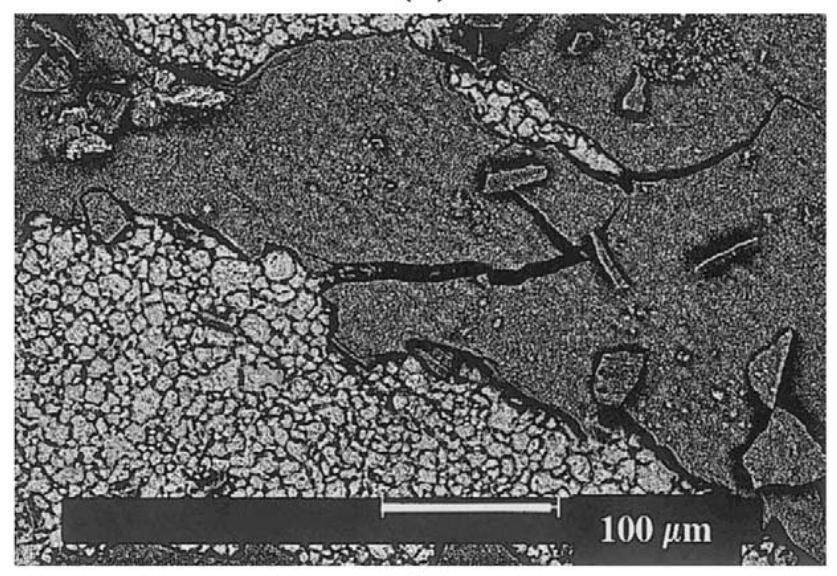

(b)

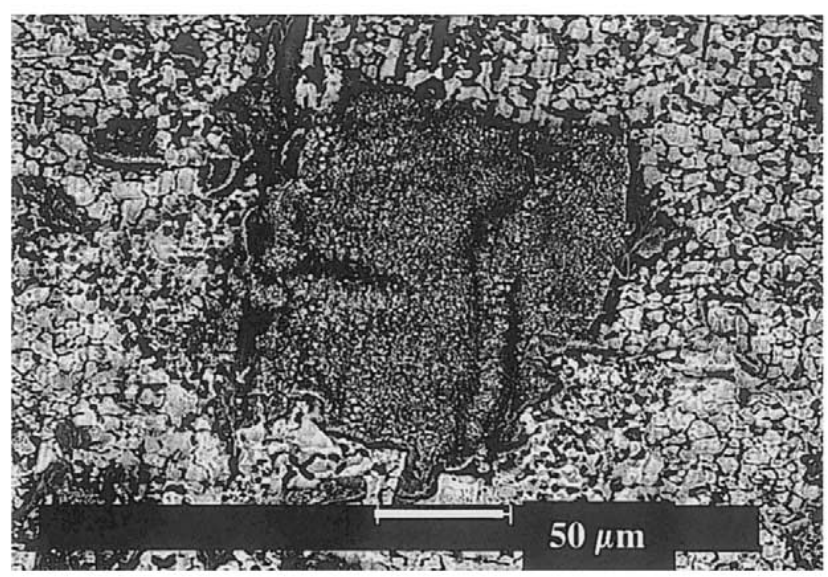

(c)

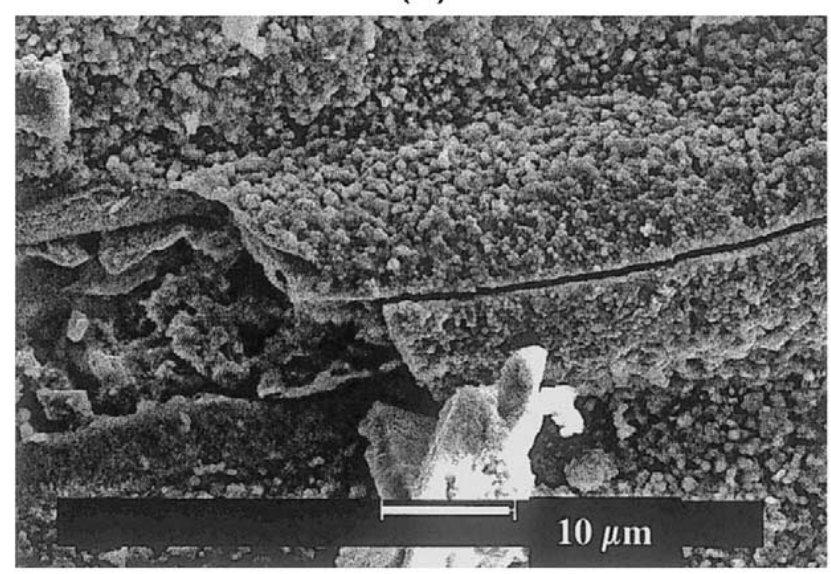

(d)

Fig. 13. Experimental evidence of wedging ( $\mathrm{a}$ and b) and buckling (c and d) modes of spallation in the austenitic material exposed at $950{ }^{\circ} \mathrm{C}$ for

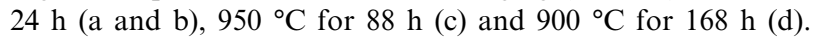

\subsection{Preferential route to spallation}

The determination of $\Delta T_{c}$ and $R$ will serve to identify the preferential route to spallation depending on the oxidation condition. Complementary microstructural investigations are used to provide experimental evidence of the different modes of spallation. The series of SEM micrographs for either short time exposure in Fig. 13(a) and (b) and long term exposure in Fig. 13(c) and (d) show the microstructure of failed scales and spalled areas for cylindrical specimens exposed at $950{ }^{\circ} \mathrm{C}$. For $24 \mathrm{~h}$ exposure (Fig. 13(a)), cross-sectional images show the occurrence of inclined compressive shear cracks within the oxide scale. These cracks develop preferentially within the scale since the substrate/oxide interface has a high adhesive strength relative to the cohesive strength of the oxide. On further cooling, the shear cracks delimit a region of interfacial decohesion where a wedge crack grows resulting in the detachment of flat spalled particles as shown in Fig. 13(b). This illustrates unambiguously the so-called wedging mode of spallation.

In the case of longer exposure, i.e. 88 or $168 \mathrm{~h}$, the shape of the zones of decohesion changes. Bowed mor- phologies are observed, resulting from an initial formation of buckles due to the compressive stress (Fig. 13(c)). This is the consequence of poor interfacial adhesion due, for instance, to an aggregation of interface defects such as voids or a segregation of detrimental elements such as sulphur. Once these zones of decohesion and related buckled regions develop, high tensile stress is likely to be generated in the oxide scale resulting in crack propagation and spall detachment (Fig. $13(d))$.

Considering the values of $\Delta T_{c}$ determined by AE, the microstructural analysis described above and the main hypothesis of the model, i.e. a poor and a high interfacial adhesion, respectively for the buckling and the wedging modes of spallation, an attempt is made to determine the preferential route to spallation.

Fig. 14 is a plot of the analytical expression of $\Delta T_{c}$ in the case of the wedging mode of spallation (Eq. (5)). A fit of the model to the experimental data determined by $\mathrm{AE}$ is sought by varying the value of the fracture energy. The best fit is found for a fracture energy of 15 $\mathrm{J} \mathrm{m}^{-2}$. However, even though this value seems appropriate for short term exposure $(24 \mathrm{~h} /$ oxide thickness 4 $\mu \mathrm{m})$, a single wedging mechanism in the whole range of 


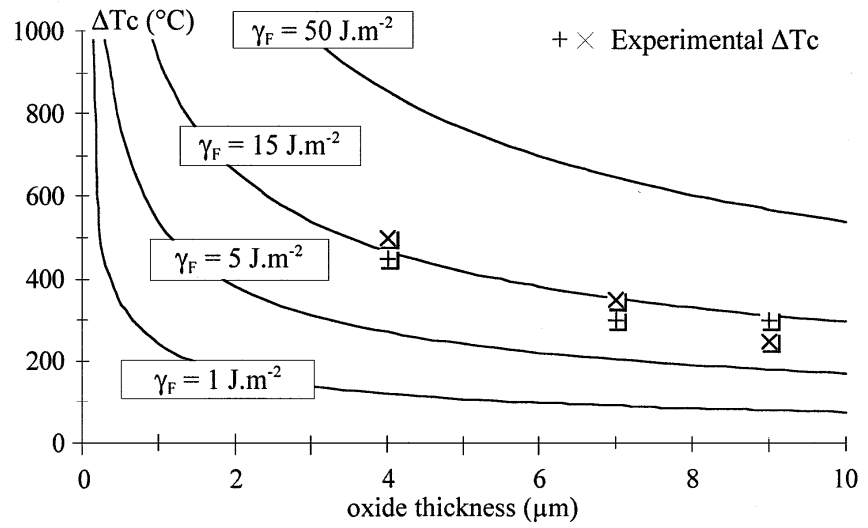

Fig. 14. Best fit of the strain energy wedging model with experimental critical temperature drop data.

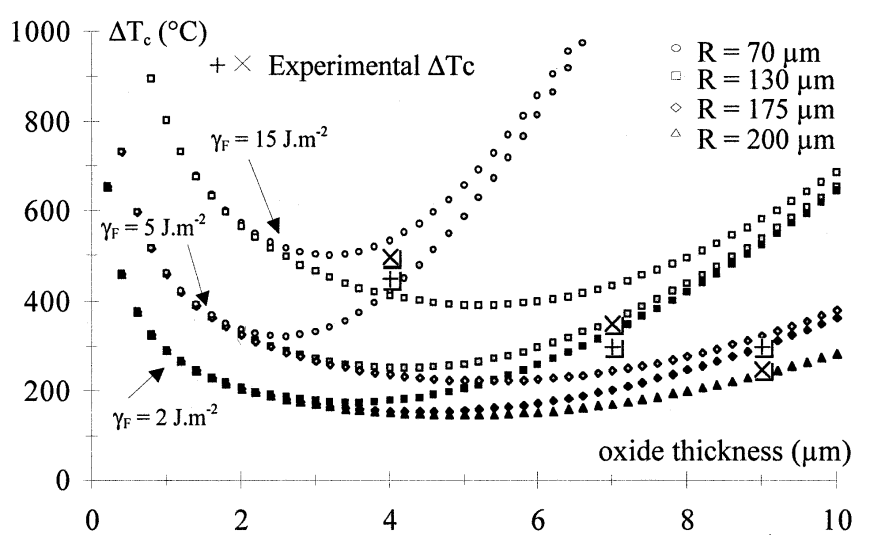

Fig. 15. Best fit of the strain energy buckling model with experimental critical temperature drop data.

exposure time, i.e. oxide thickness, is not likely to occur as experimental investigation shows that buckling preferentially develops for thicker oxide scale corresponding to 88 and $168 \mathrm{~h}$ of exposure. In other words, the fracture energy must decrease as the exposure time increases to account for the microstructural analysis and the hypothesis of the model which assumes a low fracture energy in the case of buckling allowing easy detachment and further spallation of the oxide scale.
In the case of buckling (Eq. (6)), the experimental data can be fitted satisfactorily using various combinations of $R$ and $\gamma_{F}$ values (Fig. 15). For long term exposure and taking into account the values of the spall size estimated by image analysis of SEM micrographs, it is shown that the fracture energy must be decreased by one order of magnitude with respect to the value, 15 $\mathrm{J} \mathrm{m}^{-2}$, consistent with wedging of thin oxide. A satisfactory fit is found using $R=130 \mu \mathrm{m}$ and $\gamma_{F}$ around 5 $\mathrm{J} \mathrm{m} \mathrm{m}^{-2}$ and $R=175 \mu \mathrm{m}$ and $\gamma_{F}$ around $2 \mathrm{~J} \mathrm{~m}^{-2}$ for exposure during $88 \mathrm{~h}$ (oxide thickness $7 \mu \mathrm{m}$ ) and $168 \mathrm{~h}$ (oxide thickness $9 \mu \mathrm{m}$ ), respectively. The analysis is not aimed to determine accurate values of the fracture energy but to confirm the experimentally supported hypothesis of a decrease of the energy as the exposure time increases.

It is assumed that the fracture energy may decrease as the oxidation proceeds and the oxide thickens as the consequence of the coalescence of vacancies due to the diffusion mechanism inherent to the oxidation mechanism. The vacancies concentrate into interfacial voids as shown in Fig. 16. The density of those voids increases as the exposure time increases and they provoke a loss of adherence of the oxide to the substrate thereby lowering the value of $\gamma_{F}$.

\section{Conclusion}

The oxidation behaviour of austenitic and ferritic heat resistant cast steels used for manufacturing SPF dies was investigated using gravimetric, microstructural and mechanical analysis. It was shown that both types of alloy exhibit similar behaviour in terms of oxidation kinetics and oxidation products. Isothermal and cyclic oxidation kinetics are essentially parabolic and the oxides grown at the surface of the materials are multilayer scales composed of an inner scale of $\mathrm{SiO}_{2}$, an intermediate scale of $\mathrm{Cr}_{2} \mathrm{O}_{3}$ and an outer scale of $\mathrm{MnCr}_{2} \mathrm{O}_{4}$. High temperature cycling of the materials
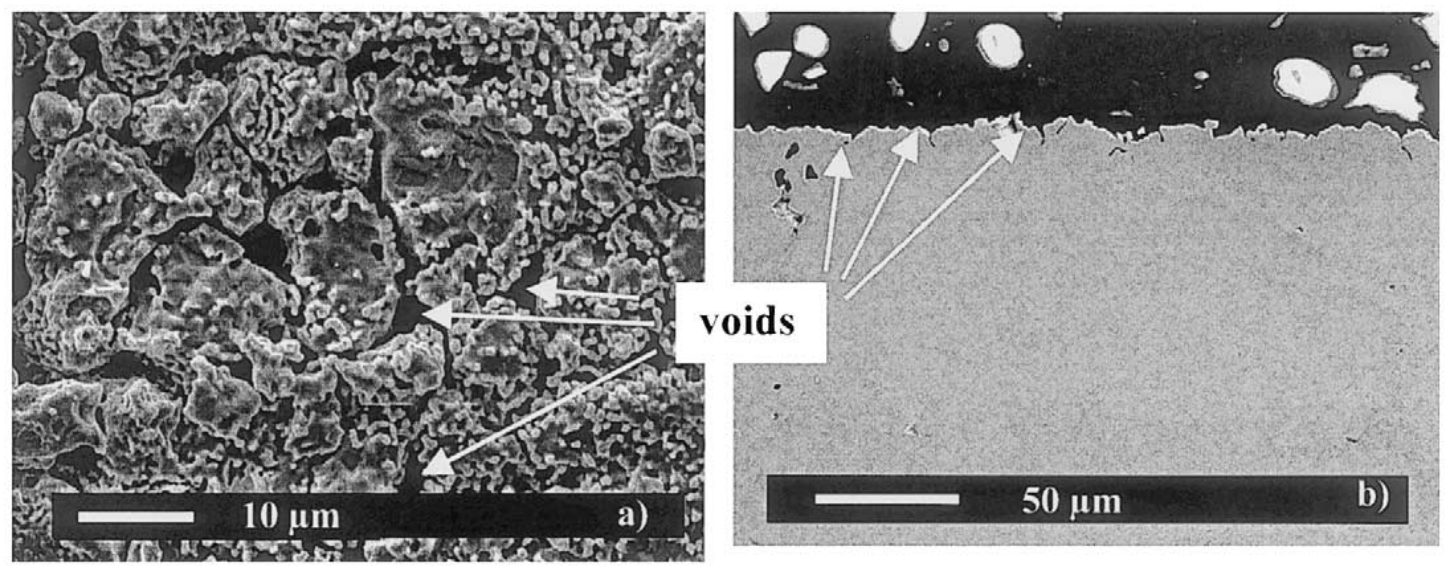

Fig. 16. SEM micrographs of the spalled surface (a) and cross-section (b) of the austenitic material exposed $150 \mathrm{~h}$ in cycle 1. 
can provoke cracking and detachment of the oxide scales provided the temperature drop exceeds $200{ }^{\circ} \mathrm{C}$. Even though cumulative cycling may increase the amount of spalled oxide, it is nevertheless the final return to room temperature that mostly damages the oxide layers.

The austenitic alloy is more prone to spallation than the ferritic alloy. The amount of spalled oxide tends to increase when the exposure time, i.e. the oxide thickness, increases. Mechanical thermoelastic analysis of the compressive stress in the oxide scales upon cooling describes satisfactorily the difference between austenite and ferrite. However, the model fails to predict the enhancement of spallation as the oxide scales thicken.

Strain energy models considering the fracture energy at the interface substrate/oxide were employed to discriminate the various routes of spallation depending on the oxide thickness. Using the values of the critical temperature drop to initiate spallation measured by $\mathrm{AE}$ and the size of spall residues estimated by image analysis of SEM micrographs coupled with microstructural analysis, it was shown that wedging and buckling modes of spallation preferentially develop for thin and thick oxides, respectively. This assumes that the fracture energy at the interface substrate/oxide decreases as the exposure time increases which may result from an enhanced segregation of voids at the interface as oxidation proceeds.

\section{References}

[1] C.H. Hamilton, A.K. Ghosh, ASM Handbook 14 (1988) 853-873.

[2] M. Blair, ASM Handbook 1 (1990) 908-929.

[3] S. Baleix, Y. Le Maoult, S. Frenois, Y. Marcel, P. Lours, G. Bernhart, Proceedings of the 3rd International Congress on Thermal Stresses, J.J. Skrzypek, R.B. Hetnarski (Eds.), Cracow, 1999, 317-320.

[4] B. Pierragi, R.A. Rapp, Acta Metallurgica 36 (1988) 1281-1289.

[5] T.A. Ramanarayanan, R. Ayer, R. Petkovic-Luton, D.P. Leta, High Temperature-High Pressures 20 (1988) 277-292.

[6] S. Baleix, S. Le Roux, G. Bernhart, P. Lours, Proceedings of the International Conference on Advances in Materials and Processing Technologies, AMPT '99, M.S.J. Hashmi, L. Looney, (Eds.), Dublin, 1999, 1175-1184.

[7] J.P. Wilber, M.J. Bennett, J.R. Nicholls, in: Cyclic Oxidation of High Temperature Materials, European Federation of Corrosion No. 27, M. Schütze, W.J. Quadakkers, (Eds.), 1999, 133-147.

[8] A.M. Huntz, S. Daghigh, A. Piant, J.L. Lebrun, Mater. Sci. Engng. A248 (1998) 44-55.

[9] S. Baleix, Thèse de l'Université Paul Sabatier de Toulouse, 1999.

[10] M.J. Bennett, J.A. Desport, P.A. Labun, Proc. Roy. Soc. Lond. A412 (1987) 223-232.

[11] J.K. Tien, J.M. Davidson, in: J.V. Cathcart (Ed.), Stress Effect and the Oxidation of Metals, AIME, New York, 1975.

[12] Y. Mikata, M. Taya, J. Comp. Mater. 19 (1985) 554-572.

[13] H.E. Evans, IMR, vol. 40, no. 1, 1995, pp. 1-40.

[14] C.H. Wells, P.S. Follansbee, R.R. Dills, in: J.V. Cathcart (Ed.), Stress Effects and the Oxidation of Metals, AIME, New York, 1975.

[15] P.Y. Hou, A. Atkinson, Mater. High Temp. 12 (1994) 119-125.

[16] W. Christl, A. Rahmel, M. Schütze, Oxidation of Metals 31 (1989) $1-34$.

[17] S. Rajendra Pillai, N. Siva Barasi, H.S. Khatak, J.B. Gnanamoorthy, Oxid. Met. 49 (1998) 509-530. 